\title{
Exploitation Evaluation of Tight Oil Reservoirs in Yanchang Formation Using Horizontal Well: A Case Study of Some Wells from Changqing Oilfield, Ordos Basin
}

\author{
Xiaoyu Cheng ${ }^{1,2}$, Fengjie $\mathrm{Li}^{1,2,{ }^{*} \text {, Youya } \mathrm{Su}^{3} \text {, Xigui Jing }}{ }^{1,2}$ \\ ${ }^{1}$ State Key Laboratory of Oil and Gas Reservoir Geology and Exploitation, Chengdu University of Technology, Chengdu, China \\ ${ }^{2}$ Institute of Sedimentary Geology, Chengdu University of Technology, Chengdu, China \\ ${ }^{3}$ Oil Production Plant 3 of Petro China Changqing Oilfield Company, Yinchuan, China
}

\section{Email address:}

lifengjie72@163.com (Fengjie Li)

${ }^{*}$ Corresponding author

\section{To cite this article:}

Xiaoyu Cheng, Fengjie Li, Youya Su, Xigui Jing. Exploitation Evaluation of Tight Oil Reservoirs in Yanchang Formation Using Horizontal Well: A Case Study of Some Wells from Changqing Oilfield, Ordos Basin. American Journal of Energy Engineering.

Vol. 5, No. 3, 2017, pp. 11-16. doi: 10.11648/j.ajee.20170503.11

Received: February 11, 2017; Accepted: May 12, 2017; Published: July 5, 2017

\begin{abstract}
Horizontal wells development technology has become an important means to improve the production of a single well. In this paper, according to the reservoir characteristics of tight oil of Yanchang Formation, some optimizations of horizontal well technology were made and applied in some wells. Through evaluating the exploitation effect concluding yield evaluation, regression and water content evaluation and single well evaluation of these wells, it can be seen that the single well production is enhanced greatly.
\end{abstract}

Keywords: Horizontal Well, Tight Oil, Horizontal Technology, Stimulated Reservoir Volume, Exploitation Evaluation

\section{Introduction}

Tight oil is the abbreviation of tight reservoir oil. Tight oil always refers to the sandstone, limestone, reservoir etc, which overlying pressure permeability is less than or equal to the $0.1 \mathrm{mD}$ [1]. Oil would be transported for a short distance and become lighter. In certain economic and technical conditions, single well, without natural productivity or which natural productivity is lower than the lower limit of industrial capacity, will obtain industrial production of oil [2, 3, 4]. Combined with the actual situation of the Ordos basin, the tight oil is divided into two types (Figure 1). Based on past experience, the formation of tight oil has three key flags: large area distribution of tight reservoirs, the wide covered distribution of high quality sapropelic source beds with high maturity, continuous distribution of symbiosis between tight reservoir and source rocks $[5,6]$.

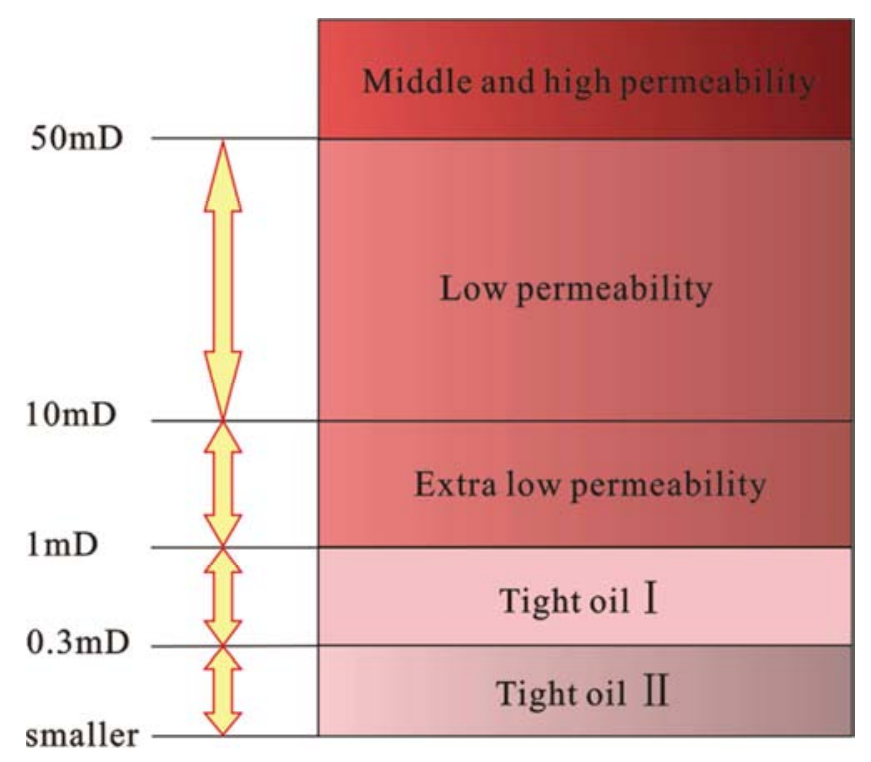

Figure 1. The division of tight oil types in Ordos basin. 
The Ordos basin has a wealth of oil and gas resources. As the most important hydrocarbon source rocks and oil gas reservoir of Mesozoic in basin, Yanchang Formation is rich in oil. And semi-deep lake and delta front sedimentary sand bodies of Chang 7 and Chang 6 reservoir are the main distribution layers of tight oil. The tight sandstone and hydrocarbon source rock in these layers contact closely. The oil layers have stable distribution and good lateral continuity. The tight oil has good properties, high liquidity and high oil saturation. Because of the symbiosis between tight sandstone reservoir and hydrocarbon source rock, filling degree of oil is high. It was found that the reservoir has poor reservoir properties, more interlayer, strong heterogeneity, natural fracture [7]. In recent years, successively finding of low permeability and ultra-low permeability oilfield in the areas of Xifeng, Jiyuan and Huaqing, then major progress in exploration and research of tight oil were made $[8,9,10,11]$.

In order to realize the effective exploitation of this kind of reservoir, Changqing Oilfield actively changes the development models from directional wells to horizontal wells. With application in oil and gas field exploration and rapid development, Horizontal well technology has become one of the focuses in petroleum industries [12]. The horizontal wells have many obvious advantages, such as high output, large reserves controlled by single well, and increasing of the recoverable reserves of crude oil. However, there are many disputes about the optimization design of horizontal well and the selection of volume fracturing technology $\left[13,14^{]}\right.$. In this paper, through the optimizing of the horizontal well pattern, contrastively analyzing and choosing preferable volume fracturing technology, as well as optimizing drilling technology, then it values the exploitation effects of tight oil of Yanchang Formation in Ordos basin used some wells from Changqing oilfield.

\section{Model Optimization and Application}

Horizontal well optimization includes three aspects, optimization technology of horizontal well pattern, fracturing technology and drilling technology. The key technical parameters of horizontal well pattern include well

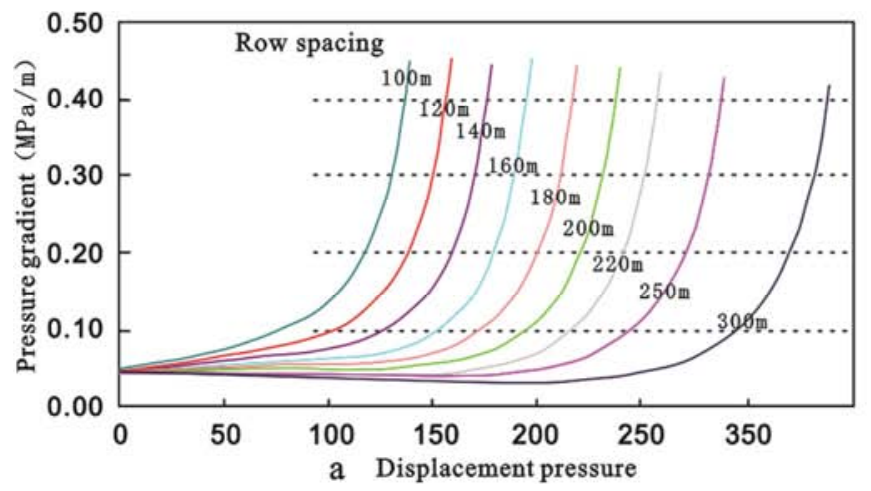

arrangement (including design of angle between fracture and horizontal section), well spacing, row spacing, horizontal length and fracture laying patterns (fracture laying density).

\subsection{Optimization of Horizontal Technology}

\subsubsection{Position Optimization of Horizontal Section}

The theoretical study shows that when the anisotropic horizontal section is perpendicular to the fracture direction, that is $\alpha=0$, the yield is the highest. When the anisotropic horizontal section is parallel to the fracture direction, that is $\alpha=$ $\frac{\pi}{2}$, the yield is the lowest (Figure 2).

$$
Q=\frac{542.9 K h\left(p_{e}-p_{W}\right)}{\mu \ln \frac{2 r_{e} \sqrt{\cos ^{2} \theta_{e}+\beta^{2} \sin ^{2} \theta_{e}}}{1 \sqrt{\cos ^{2} \alpha+\beta^{2} \sin ^{2} \alpha}}}
$$

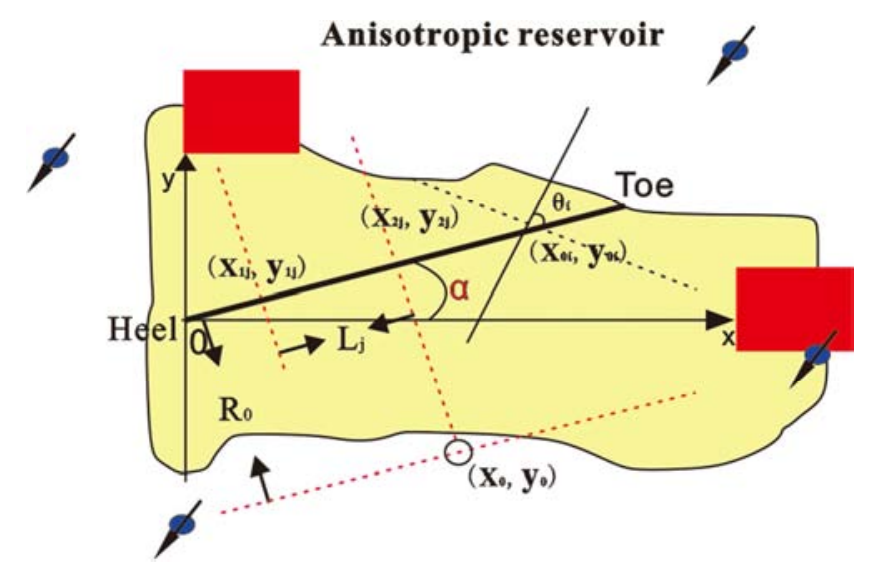

Figure 2. Diagram of angle between directions of horizontal well and fracture.

\subsubsection{Optimization of well Spacing and Row Spacing}

Core indoors experiment from Changqing 6 oil reservoir has proved that when pressure difference with 500-meter well spacing and 200-meter row spacing is greater than starting pressure gradient $(0.048 \mathrm{MPa} / \mathrm{m})$, effective pressure displacement can be established (Figure 3a, 3b).

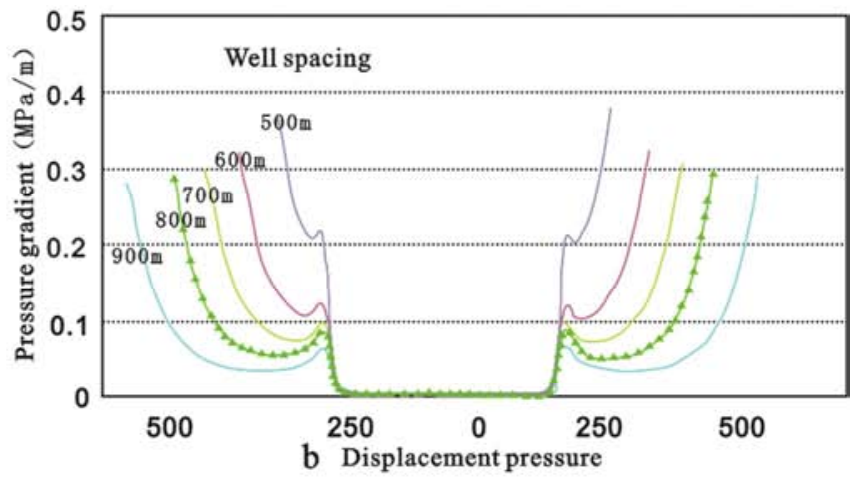

Figure 3. a. Diagram of displacement pressure and pressure gradient a: different row spacing; $b$ : different well spacing. 


\subsubsection{Optimization of Horizontal Well Pattern}

According to the numerical simulation and experience, five-point and seven-point well pattern have been adopted. About the well spacing and row spacing, $500 \times 200 \mathrm{~m}$ well pattern was used.

\subsubsection{Optimization of Horizontal Section Length}

Theoretical formulas and numerical simulations show that the longer the horizontal section, the higher the initial production of a single well.

Productivity calculation formulas of fractured horizontal well are shown as follows:

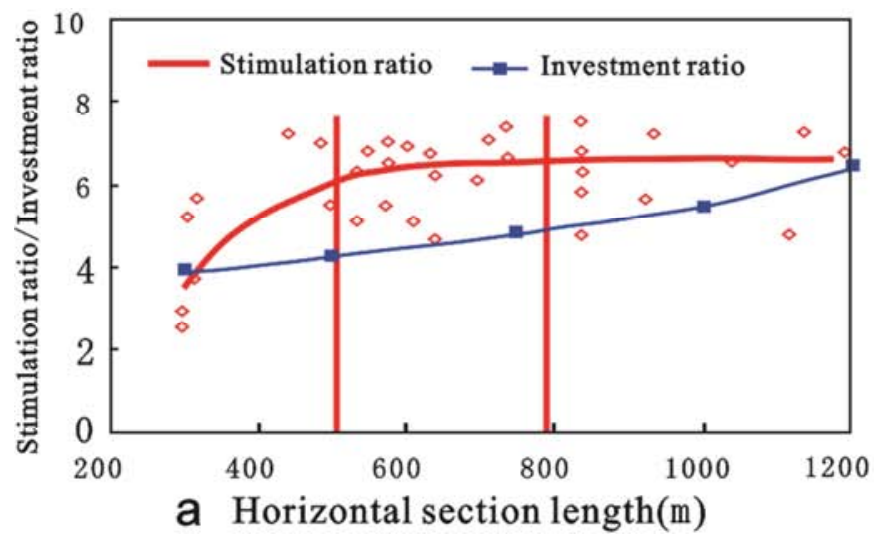

$$
\begin{gathered}
Q_{f \max }=\frac{2 \pi K h_{0} n}{\mu_{0} B_{0}} \cdot \frac{p_{e}-p_{w f}}{\operatorname{arch} \frac{\pi b}{\sin \frac{\pi L_{f}}{2 a}}+\frac{K h_{0}}{K_{f} c} \ln \frac{h_{0}}{2 r_{w}}} \\
Q_{\operatorname{mmax}}=\frac{\frac{8 \pi \mathrm{KL}\left(\mathrm{p}_{\mathrm{e}}-\mathrm{p}_{\mathrm{wf}}\right)}{\mu_{0} \mathrm{~B}_{0}}}{3 \ln \frac{\mathrm{h}_{0}}{2 \pi \mathrm{r}_{\mathrm{w}}}+\frac{2 \pi \mathrm{a}}{\mathrm{h}_{0}}}
\end{gathered}
$$

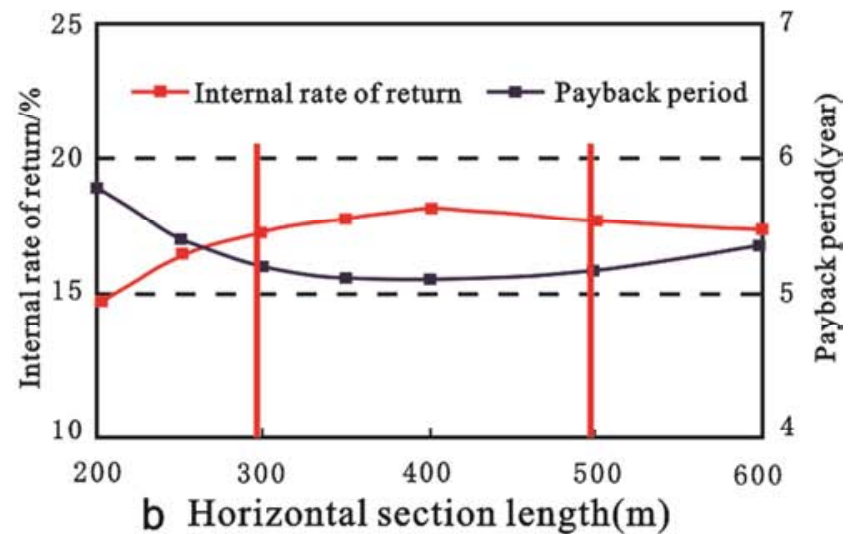

Figure 4. a. Diagram among horizontal section length, stimulation ratio and investment ratio; $b$ : among horizontal section length, internal rate of return and payback period.

Based on comprehensive evaluation of theoretical and economic efficiency, from figure $4 a$ and figure $4 b$, it can be seen that using of 500-600m horizontal section length for the five-point method and $800-1000 \mathrm{~m}$ horizontal section length for seven-point is more reasonable.

\subsubsection{Optimization of Fracture Laying Patterns}

According to the relationship between fracture density and production of a single well and economic benefits, optimum fracture number per $100 \mathrm{~m}$ is $1-1.5$ (Figure 5).

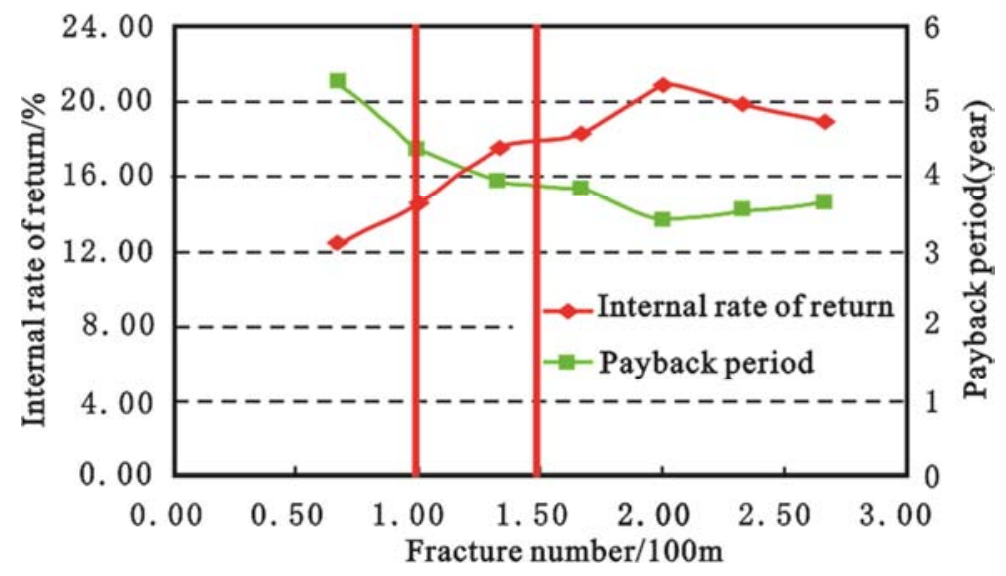

Figure 5. Diagram among fracture density, internal rate of return and payback period.

\subsection{Optimization of Stimulated Reservoir Volume}

\subsubsection{Matching Technologies and Its Characteristics}

In horizontal well development test area of Chang $8_{1}$ well in the block of Huang 36, Chang $6_{3}$ well in the block of Yan, Chang $7_{2}$ in the block of $\mathrm{Wu}$, PSK staged multi-section fracture, annuls sand fracture and normal staged fracturing technology were carried out. It was realized that making the fracture laying dense and liberating oil layer highly. Displacement of annuls sand fracture is up to $2.5 \uparrow 6 \mathrm{~m}^{3} / \mathrm{min}$. The volume increased by $50 \%$ by alteration of single stage fracture. It can be formed that Multi-direction and multi-dimension fracture and entirely breaking of reservoirs using normal staged fracturing technology.

The single well productivity of the horizontal well by 
stimulated reservoir volume is 6-8 times than that by conventional development well (Figure 6).

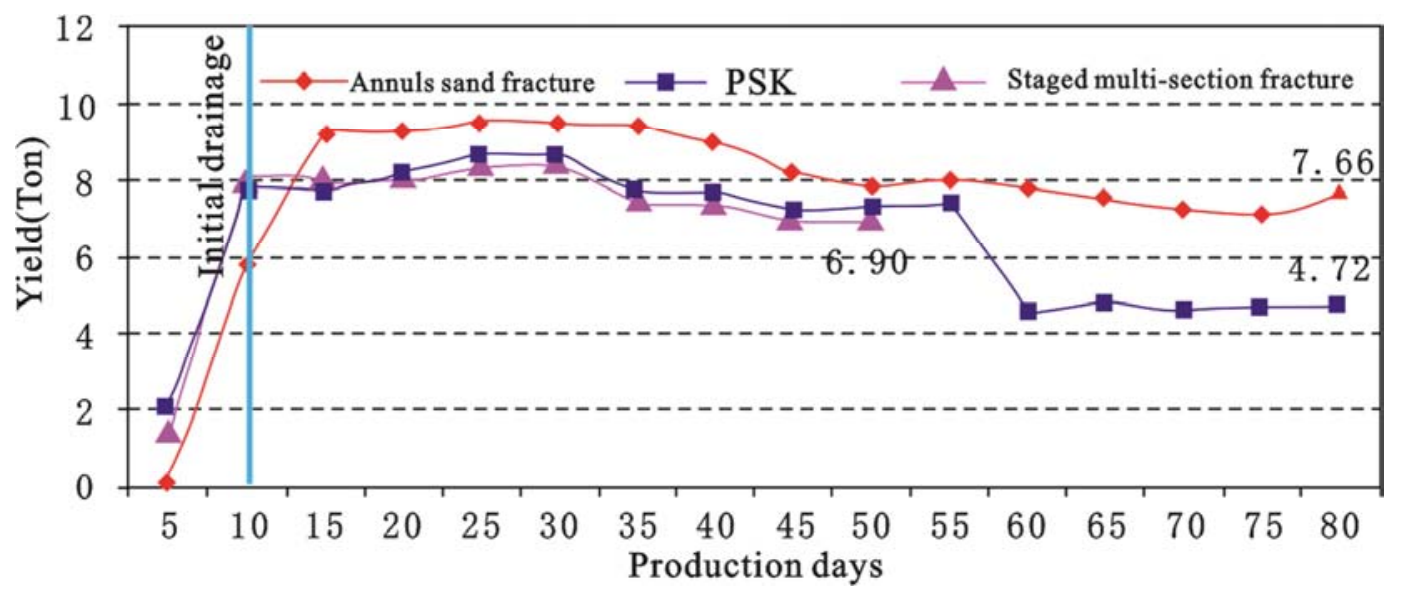

Figure 6. Production curves of different technologies well.

\subsubsection{Optimization of Matching Technologies}

By comparing the three aspects of the initial production, decline rate and construction period after renovation of three processes, it was concluded that annuls sand fracture would be more applicable with high production, low decline rate and equivalent oil-test cycle. The initial production of single well was up to 12.9 tons in the two wells in Chang $7_{2}$, Wu 464 area by annuls sand fracture. So, annuls sand fracture is better.

\subsection{Optimization of Drilling Technology}

The position of entering window was optimized to the lower part of the second opening well. When well track enters into the oil layer, well deviation is less than $76^{\circ}$. Then the drilling cycle and reduced the drilling cost were shortened by above measures. Well construction period was reduced to 23.8 days per well.

\section{Evaluation of Exploitation Effect}

\subsection{Yield Evaluation}

Comparing the single well output between horizontal wells

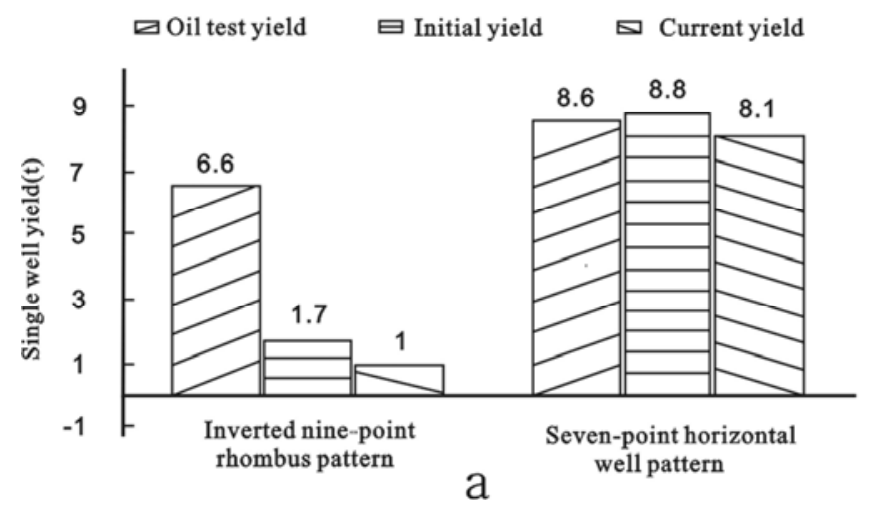

and directional wells in blocks of Huang 36, Yan 31 and $\mathrm{Wu}$ 464 , the former is 6-8 times than the latter. The earlier average daily oil was 1.7 tons, but now 1.0 tons by inverted nine-point rhombus pattern of horizontal wells in Huang 36 block. When the pattern was optimized to seven-point well pattern, the earlier average daily oil was 8.8 tons, but now 8.1 tons. The earlier average daily oil was 1.3 tons, but now 0.6 tons by inverted nine-point rhombus pattern of horizontal wells in Yan 31 block. When the pattern was optimized to seven-point well pattern, the earlier average daily oil was 6.5 tons, but now 6.1 tons. The earlier average daily oil was 5.1 tons, but now 1.9 tons by inverted nine-point rhombus pattern of horizontal wells in $\mathrm{Wu} 464$ block. When the pattern was optimized to seven-point well pattern, the earlier average daily oil was 10.2 tons, but now 10.1 tons.

\subsection{Regression and Water Content Evaluation}

Contrasting decline and water content after exploitation by horizontal wells and directional wells in blocks of Huang 36, Yan 31 and $\mathrm{Wu} 464$, risk of seeing water is relatively small from figure $7 \mathrm{a}$ and $7 \mathrm{~b}$. The regression was controlled among $1.9-7.9 \%$, water content among $24.7-42.1 \%$.

$\boxminus \quad$ Regression(\%) $\square$ Moisture content(\%)

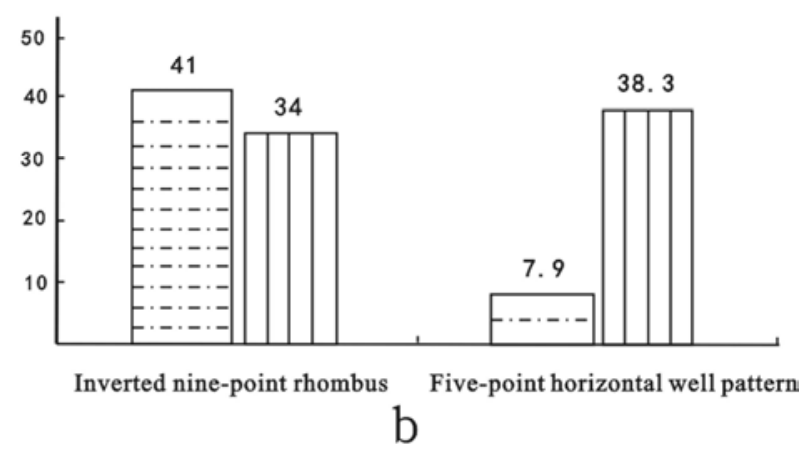

Figure 7. a. Comparison between horizontal well and directional well a: single well yield; $b$ : water content and regression.

\subsection{Single Well Ealuation}

The well pattern was five-point, $500 \mathrm{~m}$ of horizontal section length with 1.3 fractures per $100 \mathrm{~m}$ in wells of YP 32-17. Stimulated reservoir volume retention fluid was up to 2138 cubic meter showing a longer stable period and efficient 
exploitation of horizontal well. Daily output of single well was 10.5 tons (Figure 8a). The well pattern of seven-point, $800 \mathrm{~m}$ of horizontal section length, and 1.5 fractures per $100 \mathrm{~m}$ was applied in wells of HP35-22. Stimulated reservoir volume
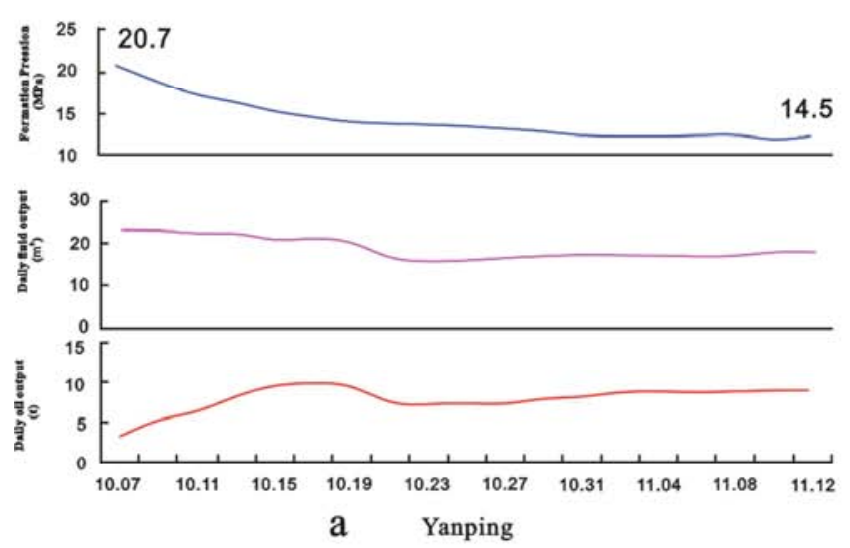

Figure 8. Daily output curve a: YP32-17 wells; b: HP 35-32 wells.

\section{Conclusion}

Through the optimized exploitation technology, single well daily oil production can reach more than 8 tons, to achieve the effective development of tight oil resources. The $500 \times 200 \mathrm{~m}$ well pattern was more reasonable after optimization. Horizontal section length is $500-600 \mathrm{~m}$ for five-point. Horizontal section length is $800-1000 \mathrm{~m}$ for seven-point. The Regression was controlled among 1.9-7.9\%, water content among $24.7-42.1 \%$ by horizontal well pattern. As for development of tight oil, the technology of "horizontal well + stimulated reservoir volume" has been carried out. Retention fluid of stimulated reservoir volume can make up ability of formation and restore the original formation pressure to $131 \%$. It has stable production period and high efficiency development of horizontal well. It was found that the yield was positively correlated with construction parameters by the field practice. The initial production of horizontal well can reach 8 tons or more with greater than or equal to $800 \mathrm{~m}$ of horizontal section length, $4 \mathrm{~m}^{3} / \mathrm{min}$ of fracturing displacement, $4000 \mathrm{~m}^{3}$ of amount of fluid into the ground and 1 piece per $100 \mathrm{~m}$ of fracture laying density

\section{Nomenclature}

$Q_{f \max }$ horizontal section flow in the direction of substrate

$Q_{\max }$ horizontal section flow in the direction of fracture

$\mathrm{n} \quad$ number of fracture

c width of fracture

$\mathrm{L}_{\mathrm{f}} \quad$ length of fracture

$\mathrm{h}_{\mathrm{f}} \quad$ height of fracture

$\mathrm{K}_{\mathrm{h}} \quad$ permeability of substrate

$\mathrm{K}_{\mathrm{f}} \quad$ permeability of fracture

$\mathrm{h}_{0} \quad$ height oil reservoir

$\beta \quad$ anisotropy coefficient

L length of horizontal section retention fluid was up to 6282 cubic meter. The yield and water content was stable at present. Daily oil output was kept stably at 11.5 tons (Figure $8 b$ ).
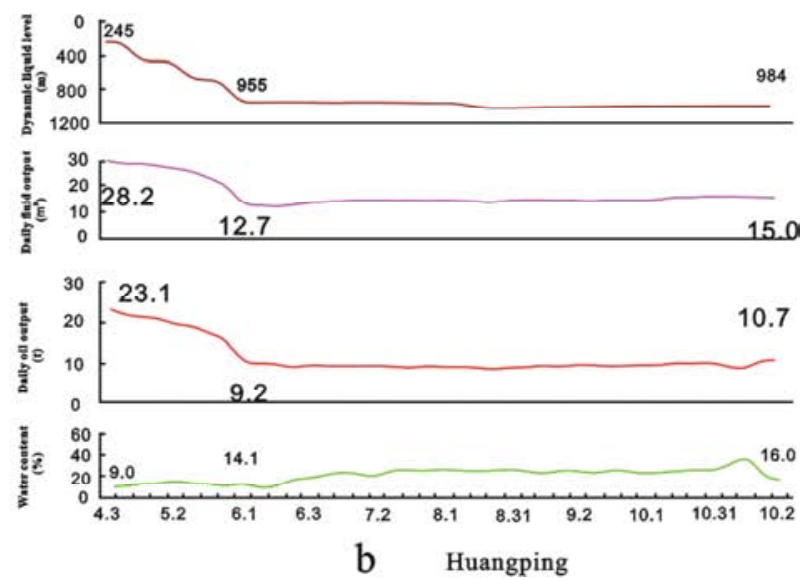

$\mathrm{p}_{\mathrm{e}} \quad$ supply edge pressure

$\mathrm{p}_{\mathrm{wf}} \quad$ bottom hole pressure

\section{References}

[1] Petzet, A. (2006). Billions of barrels in Bakken recovery seen in Williston. Oil \& Gas Geology 106 (46): 42-48.

[2] Law, B. E., Curtis, J. B. (2002). Introduction to unconventional petroleum system. AAPG Bulletin 86 (11): 1851-1852.

[3] Dou, H. E., Ma, and S. Y. (2012). Lessons learned from oil production of tight oil reservoirs in Bakken play. Oil Drilling \& Production Technology 42 (3): 120-124.

[4] Love, T. G., McCarty, R. A., and Surjaatmadja, J. B. (2001). Selectively placing many fractures in openhole horizontal wells improves production. SPE 16 (4): 219-224.

[5] Zhang, N. N., Liu, L. F., and Su, T. X. (2013). Comparison of Chang 7 Member of Yanchang Formation in Ordos basin with Bakken Formation in Williston Basin and Significance. Geoscience 27 (5): 1120-1130.

[6] Guo, Y. R., Liu, J. B., and Yang, H. (2012). Hydrocarbon accumulation mechanism of low permeable tight lithologic oil reservoirs in Yanchang Formation, Ordos Basin. Petroleum Exploration and Development 39 (4): 417-424.

[7] Yao, J. L., Deng, X. Q., and Zhao, Y. D. (2013). Characteristics of tight oil in Triassic Yanchang Formation, Ordos Basin. Petroleum Exploration and Development 40 (2): 150-158.

[8] Deng, X. Q., Liu, X. S., and Li, S. X. (2009). The relationship between compacting history and hydrocarbon accumulating history of super-low permeability reservoirs in the Triassic Yanchang Formation, Ordos Basin. Oil \& Gas Geology 30 (2): 156-161.

[9] Yang, H., Fu, J. H., and He, H. Q. (2012). Formation and distribution of large low-permeability ithologic oil regions in Huaqing, Ordos Basin. Petroleum Exploration and Development 39 (6): 641-648. 
[10] Yang, H., Li, S. X., and Liu, X. Y. (2013). Characteristics and resource prospects of tight oil and shale oil in Ordos basin. Acta Petrolei Sinica 34 (1): 1-11.

[11] Zhao, J. Y., Fan, J. M., and He, Y. H. (2015). Optimization of horizontal well injection-production parameters for ultra-low permeable-tight oil production: A case from Changqing Oilfield, Ordos Basin. Petroleum Exploration and Development 42 (1): 68-75.

[12] Crosby, D. G., Rahman, M. M., and Rahman, M. K. (2002). Single and multiple transverse fracture initiation from horizontal wells. Journal of Petroleum Science and Engineering 35 (3): 192-204.

[13] Lian, L. M., Jiang, H. Q., and Niu, J. L. (2012). Research on multi-objective optimization method of horizontal injection-production patterns. Petroleum Geology and Recovery Efficiency 19 (1): 85-90.

[14] Zhao, J. Y., He, Y. H., and Fan, J. M. (2014). Optimization technology study for horizontal well pattern in ultra-low permeable tight reservoirs. Journal of Southwest Petroleum University: Science \& Technology Edition 36 (2): 1-98. 